Mohd Suhari \& Mohd Farid, "Pembangunan Spiritual dalam Pelaksanaan Program Tarbih," Afkār Vol. 20 Issue 2 (2018): 127-158

\title{
PEMBANGUNAN SPIRITUAL DALAM PELAKSANAAN PROGRAM TARBIAH DI ASRAMA SEKOLAH-SEKOLAH MENENGAH KEBANGSAAN AGAMA (SMKA) PULAU PINANG
}

SPIRITUAL DEVELOPMENT IN THE IMPLEMENTATION OF TARBIAH PROGRAMME AMONG BOARDING STUDENTS AT SELECTED NATIONAL RELIGIOUS SECONDARY SCHOOLS (SMKA) IN PENANG

Mohd Suhardi Mat Jusoh ${ }^{*} \&$ Mohd Farid Mohd Sharif**

*Centre for Modern Language \& Human Sciences. Universiti Malaysia Pahang. 26300. Kuantan. Pahang. Malaysia.

${ }^{* *}$ School of Humanities. Universiti Sains Malaysia. 11800. Pulau Pinang. Malaysia.

Email: *suhardi@ump.edu.my

DOI: https://doi.org/10.22452/afkar.vol20no2.4

\section{Khulasah}

Kajian ini meneliti aspek pembangunan spiritual dalam pelaksanaan program tarbiah di asrama Sekolah-Sekolah Menengah Kebangsaan Agama (SMKA) Pulau Pinang yang terdiri daripada SMKA al-Mashoor (L), SMKA al-Mashoor (P), SMKA alIrsyad dan SMKA Nibong Tebal. Objektif utama kajian ini adalah untuk mengenalpasti sejauhmana elemen-elemen pembangunan spiritual diterapkan dalam pelaksanaan program tarbiah, menilai penglibatan guru asrama sebagai murabbi serta melihat keberkesanan program tarbiah dalam pembangunan spiritual pelajar. Kajian ini berbentuk penerokaan dwi-cara di mana data-data kualitatif dikumpul melalui kaedah pemerhatian dan temubual secara separa tertutup, sementara data kuantitatif diperolehi melalui soal selidik. Secara keseluruhan, dapatan kajian kualitatif menunjukkan bahawa elemen pembangunan spiritual iaitu mujähadah al-nafs dan al-ihsān dalam penunaian ibadat fardu dan sunat 
hanya mampu dihayati oleh sebilangan kecil responden sahaja. Secara tidak langsung, dapatan ini menunjukkan penglibatan guru asrama sebagai murabbi dalam pembangunan spiritual pelajar berada di tahap yang sangat sederhana. Oleh itu, dapatan kajian kuantitatif telah mengesahkan bahawa penglibatan guru asrama sebagai murabbi dan manhaj pembangunan spiritual dalam program tarbiah berada di tahap min sederhana tinggi $(\min =3.78$ dan 3.18). Begitu juga, analisis statistik inferensi berdasarkan ujian ANOVA sehala menunjukkan tidak terdapat perbezaan yang signifikan $(p=0.42, p>0.05)$ di antara tempoh masa responden tinggal di asrama dalam menjelaskan keberkesanan program tarbiah terhadap pembangunan spiritual pelajar di asrama. Justeru, kajian ini menyimpulkan bahawa pembangunan spiritual dalam pelaksanaan program tarbiah di asrama SMKA Pulau Pinang memerlukan organisasi murabbī yang mantap bagi merealisasikan objektif pembangunan spiritual dalam pembentukan sahsiah pelajar di SMKA.

Kata kunci: Pembangunan spiritual; mujāhadah alnafs; al-ihsān; murabbī.

Abstract
This study is to explore the aspects of spiritual
development in the implementation of tarbiah
programmes at selected National Religious Secondary
Schools or SMKA in Penang that consist of SMKA al-
Mashoor (L), SMKA al-Mashoor (P), SMKA al-
Irsyad and SMKA Nibong Tebal. The main objective
of this study is to identify how far the elements of
spiritual development are applied in the
implementation of the programme, evaluating the
involvement of hostel teachers as murabbi and to
comprehend the effectiveness of the tarbiah
programme towards students' spiritual development.
This study is an exploratory mix-method research with
the qualitative data collected through observation and
partially-closed interview methods, while the


quantitative data is obtained through questionnaires. Overall, the findings from the qualitative part highlighted that only a small number of respondents implemented the elements of spiritual development of mujāhadah al-nafs and al-ihsān. This indirectly revealed that the participation of boarding teachers as murabbi in the student's spiritual development is at a moderate stage. However, the findings from the quantitative part of the study further confirmed the involvement of boarding teachers as murabbi and manhaj of spiritual development was at a medium high mean $(\min =3.78$ and 3.18). Similarly, the inferential statistical analysis based on a one-way ANOVA test shows that there is no significant difference $(p=0.42$, $p>0.05$ ) between the length of time the respondent resides in the hostel when explaining the effectiveness of student's spiritual development through tarbiah programme. Hence, this study concludes that the spiritual development in the implementation of the tarbiah program at SMKA Penang hostel requires a systematic and efficient murabbi organization to realize the objective of spiritual development in the formation of students' character.

Keywords: Spiritual development; mujāhadah alnafs; al-ihsān; murabbì.

\section{Pendahuluan}

Dalam perspektif tarbiah Islam, pembentukan nilai dan kecemerlangan insan berteraskan aspek kesucian hati merupakan asas terpenting yang menentukan keberhasilan dan kejayaaan dalam proses pembangunan manusia. Ini kerana aspek kerohanian merupakan intisari manusia yang sebenar dan ciri-ciri peribadinya, bahkan kebaikan ruh adalah punca kebaikan seseorang dan masyarakat seluruhnya. ${ }^{1}$ Sehubungan itu, aspek pembangunan manusia menurut perspektif Islam berbeza sama sekali

\footnotetext{
${ }^{1}$ Muhammad Quțb, Manhaj al-Tarbiyah al-Islāmiyyah (Qāhirah: Dār alShurūq, 1993), 40.
} 
dengan sistem sekular yang hanya memberi perhatian terhadap aspek pembangunan akal dan jasad sematasemata.

Secara jelas, pembangunan aspek kerohanian tidak dititiberatkan. Akibatnya, proses penilaian terhadap pencapaian dan pembangunan manusia menjadi lebih rumit dan sukar ditentukan iaitu adakah seseorang itu telah membangun secara seimbang dan menyeluruh dalam konteks pendidikan semasa hari ini. Implikasinya, terdapatnya jurang yang ketara di antara amalan semasa pelaksanaan sistem pendidikan dan Falsafah Pendidikan Kebangsaan terutamanya dalam isu pembangunan domain spiritual. ${ }^{2}$ Justeru, sekali pun kemajuan ilmu, teknologi dan industri telah dapat memberikan pelbagai kemudahan dan kesenangan kepada manusia di abad ini namun semuanya itu belum dapat menjamin kesejahteraan dan ketenangan jiwa. $^{3}$

Dengan itu, jelaslah aspek kerohanian memainkan peranan yang amat bermakna dalam proses pembangunan manusia kerana ia dapat membentuk tingkah laku, tindakan dan keputusan seseorang dan dengan itu juga, krisis kejiwaan yang berlaku dapat diatasi jika manusia kembali kepada ajaran-ajaran agama dengan melakukan penyucian jiwa seperti yang disarankan oleh al-Qur'an. ${ }^{4}$ Bagi memenuhi objektif ini, maka semestinya aspek pembangunan spiritual perlu dijadikan teras utama dalam konteks pelaksanaan program pendidikan Islam sama ada yang berbentuk formal atau informal.

2 Rohana Hamzah et.al., "Spiritual Education Development," International Journal of Islamic and Arabic Education, Bil. 2, No. 2, Januari 2010, 1-12.

3 Mahsyuri, "Prinsip-Prinsip Tazkiyah al-Nafs dalam Islam dan Hubungan dengan Kesihatan Mental," Jurnal Pemikiran Islam, Bil. 37, No. 2 (Januari 2012), 95.

4 Zidni Nuran Noordin et.al., "Perbandingan Proses Tazkiyah al-Nafs Menurut Imam al-Ghazali dan Ibnu Qayyim," Jurnal al-Turath, Bil. 2, No. 1 (Mac 2017), 44. 


\section{Program Tarbiah di Asrama Sekolah Menengah Kebangsaan Agama (SMKA), Pulau Pinang}

Di Pulau Pinang, sekolah-sekolah menengah kebangsaan agama (SMKA) yang menjadi fokus kajian dalam pelaksanaan program tarbiah di asrama adalah seperti berikut:

i. SMKA al-Mashoor (L)

ii. SMKA (P) al-Mashoor

iii. SMKA al-Irsyad

iv. SMKA Nibong Tebal

Secara umumnya, pelaksanaan program tarbiah di sekolah-sekolah berkenaan adalah berpandukan kepada Modul Pembangunan Murid Asrama (MPMA), Program Kecemerlangan Sahsiah SMKA serta Buku Panduan Pengurusan Asrama, Kementerian Pelajaran Malaysia (KPM). Sehubungan itu, matlamat utama pelaksanaan program ini adalah pembentukan sahsiah tinggi, beriman dan bertaqwa dalam kalangan pelajar sekolah-sekolah agama berkenaan seperti yang dihasratkan dalam Falsafah Pendidikan SMKA. 5

Dalam aspek ini, program tarbiah berfungsi sebagai suatu bentuk didikan atau kegiatan keagamaan bagi memenuhi tujuan asasi didikan agama iaitu supaya agama dapat mempengaruhi jiwa murid-murid dan kesannya dapat dilihat pada perangai dan pergaulan mereka dengan masyarakat. Kenyataan ini adalah selari dengan hasrat Kementerian Pelajaran Malaysia (KPM) iaitu keberkesanan pentadbiran, konsep dan falsafah asrama bukan sahaja dinilai dari segi kecemerlangan akademik penghuninya tetapi diukur juga dari segi keadaan hidup para pelajar di asrama. $^{6}$

5 Jabatan Pendidikan Islam dan Moral, Kementerian Pendidikan Malaysia, Program Kecemerlangan Sekolah Menengah Kebangsaan Agama, Iklim Sekolah (Kuala Lumpur: JAPIM/KPM, 1997), iii.

${ }^{6}$ Buku Panduan Pengurusan Asrama Sekolah, Bahagian Pengurusan Sekolah Harian (Kementerian Pelajaran Malaysia, t.t.), 108. 
Selain itu, keprihatinan Kementerian Pelajaran terhadap aspek penampilan sahsiah pelajar dapat dilihat secara jelas dalam pernyataan berikut:

"Harus diingat bahawa penampilan pelajar dalam masyarakat mencerminkan corak pendidikan yang diterimanya di sekolah. Matlamat pendidikan negara untuk menghasilkan pelajar yang berilmu pengetahuan, berakhlak mulia serta berketrampilan tidak akan tercapai sekiranya pelajar masih belum dapat menunjukkan tahap pengurusan diri yang tinggi. "

Bagi memenuhi objektif di atas, program tarbiah di asrama SMKA dilihat sebagai suatu pendidikan non-formal yang dapat merealisasikan objektif pendidikan Islam formal dari sudut pengaruh timbal balik dan hubungan yang komplementari ${ }^{8}$ khususnya dalam aspek pembentukan personaliti diri seseorang murid. Ini kerana program ini menekankan aspek pembangunan sahsiah diri pelajar melalui amalan-amalan kerohanian berikut:

i. Amalan solat fardu berjemaah

ii. Amalan qiyām al-layl

iii. Amalan tilawah al-Qur'an

iv. Amalan zikir

v. Amalan puasa sunat

Dalam konteks pembangunan spiritual, ibadat fardu dan sunat di atas merupakan amalan kerohanian yang mampu membina jati diri pelajar di sekolah-sekolah berkenaan. Aspek ini adalah selari dengan manhaj pendidikan spiritual iaitu mempertingkatkan ibadah merupakan di antara teras utama dalam kerangka pembangunan spiritual seseorang. Ini kerana ibadah bukan

${ }^{7}$ Buku Panduan Pengurusan Asrama Sekolah, 40.

${ }^{8}$ Mohd. Kamal b. Hassan et.al., Pendidikan Koleksi Dakwah (Kuala Lumpur: Yayasan Dakwah Islamiah Malaysia, 1981), 4. 
sahaja dapat mempertingkatkan keimanan seseorang tetapi turut membantu seseorang mengatasi masalah dalam kehidupannya kerana ibadah dapat menghubungkan terus seseorang hamba dengan pencipta-Nya. ${ }^{9}$

\section{Murabbī dan Pembangunan Spiritual}

Dalam konteks tarbiah, tugas dan peranan asasi seseorang murabbī bukan sahaja dalam aspek kerja-kerja pengajaran, ${ }^{10}$ bahkan tugasnya yang sebenar adalah lebih terarah kepada aspek pembinaan kerohanian muridmuridnya. Sehubungan itu, dia dituntut agar memiliki keperibadian yang unggul bagi murid-muridnya ${ }^{11}$. Selain itu, dia juga seharusnya berperanan sebagai seorang penonton diri, perkembangan ilmu, rohani dan moral seseorang muridnya secara bertahap sampailah kepada kesempurnaan tujuan kejadiannya sebagai insan. ${ }^{12}$

Oleh itu, seseorang murabbī seharusnya memenuhi kriteria-kriteria yang berikut:

i. Tujuan, tingkah laku dan pemikirannya bersifat rabbān $\bar{l}^{-13}$ iaitu seluruh aktiviti dan kegiatan pendidikannya adalah untuk menjadikan muridmuridnya rabbāniyysin ${ }^{14}$ iaitu mereka dapat melihat

${ }^{9}$ Salasiah Hanin Hamjah, Pendekatan Kaunseling Spiritual Menurut alGhazali (Kuala Lumpur: Dewan Bahasa dan Pustaka, 2016), 112.

${ }^{10}$ Ghazali bin Basri, "Peranan Pendidik dalam Pembentukan Ummah," Jurnal Pendidikan Islam, Bil. 5, No. 6 (Julai 1987), 19.

${ }^{11}$ Mohammad Sharif Khan, Education Religion and the Modern Age (New Delhi: Ashish Publishing House, 1990), 103.

${ }^{12}$ Muhammad 'Uthman El-Muhammady, "Pendidikan Islam menurut alNadwi: Satu Analisis,” Jurnal Usuluddin, Bil. 11 (Julai 2000), 117.

13 Berdasarkan ayat 79, surah Āli 'Imrān, lafaz rabbān̄̄ disandarkan kepada $a l-R a b b$ iaitu seseorang yang mengetahui hakikat ketuhanan serta bersungguh- sungguh melakukan ketaatan kepada-Nya. Sila lihat Wahbah al-Zuhaylī, al-Tafsìr al-Munīr fì al-'Aqìdah wa alSharī'ah wa al-Manhaj (Damsyiq: Dār al-Fikr, 1991), 3:274.

${ }^{14}$ Di antara maksud rabbāniyyīn ialah ahli hikmah yang bertaqwa (al-Hukāmā' al-Atqiyā') iaitu mereka yang mendidik manusia serta memperbaiki urusan kehidupan mereka. Sila lihat al-Ṭabārī, Tafsìr al-Ṭabarī (Beirūt: Dār al-Kutub al-'Ilmiyyah: 1991), 3:325. 
tanda-tanda kebesaran Allah SWT, lalu menghubungkan tanda-tanda tersebut dengan setiap ilmu yang dipelajarinya. ${ }^{15}$

ii. Ikhlas iaitu seluruh kegiatan pendidikan yang diceburinya adalah untuk mendapatkan reda Allah SWT semata-mata. Sekiranya dia menginginkan pangkat atau jawatan atau seumpamanya, maka jadilah segala usahanya itu sia-sia. ${ }^{16}$

iii. Luhur keperibadiannya iaitu teguh pendiriannya agar dia mampu mempengaruhi murid-muridnya. ${ }^{17}$

Dengan itu, seseorang murabbī sama ada sebagai seorang ibu, bapa, guru atau $d \bar{a}$ ' $i$ yang mursyid seharusnya tertanam di dalam jiwanya sifat rahmat dan belas kasihan ${ }^{18}$ agar didikannya terkesan kepada seseorang dari sudut personaliti dan perubahan tingkah lakunya. Selain itu, seseorang murabbī seharusnya juga dapat memikul tanggungjawab, membantu pertumbuhan dan perkembangan serta mendidik seseorang muridnya secara berkesan seperti yang digambarkan dalam pernyataan berikut:

"Fundamentally, murabbi conveys the meaning of; bearer, fosterer, rearer, feeder or nurturer. The term al-Rabb in the Qur'an is semantically related to murabbī. Al-Rabb as in the Qur'an refers to the nourisher and possessor of all the

15 'Abd al-'Azīz al-Mu'āyațah, al-Madkhal ilā Usūl al-Tarbiyyah alIslāmiyyah (Qāhirah: Dār al-Tawzī‘ wa al-Nashr al-Islāmiyyah. 1994), 174.

16 Fu'ad bin 'Abd al-'Azīz, al-Mu'allim al-Awwal, Qudwah likull Mu'allim wa Mu 'allimah (Riyāḍ: Dār al-Qāsim, 1997), 11.

${ }^{17}$ Muḥammad Rawwās Qal'ahj̄̄, Dirāsah Taḥlīliyyah li Shakhsiyyah alRasūl Muhammad S.A.W. (Beirūt: Dār al-Nafā'is, 1996), 268.

18 Musțafā Muḥammad al-Ṭahān, al-Tarbiyah wa Dawruhā fĩ Tashkīl al-Sulūk (Mansūrah: Dār al-Wafā' lī al-Ṭibā'ah wa al-Nashr wa alTawzī', 2006), 155. 
non - Rabbis, for He being the nurturer and the lord. " 19

Dalam perspektif al-Qur'an pula, secara jelas peranan murabbi diisyaratkan kepada para nabi serta pengikut mereka yang melaksanakan dua tugas utama iaitu: ${ }^{20}$

i. Al-Tazkiyah iaitu membersih dan meninggikan jiwa manusia selaras dengan kehendak pencipta-Nya serta memeliharanya dari unsur kejahatan dan menjaga fitrah semulajadinya.

ii. Al-Ta'lìm iaitu memindahkan akidah ke dalam akal dan jiwa orang-orang mukmin untuk diterjemahkan dalam aspek tingkah laku dan kehidupan mereka.

Oleh itu, keberadaan dan bimbingan seseorang murabbī dalam konteks pembangunan spiritual seseorang dianggap sebagai syarat mutlak bagi memastikan keberhasilan pengembangan spiritualnya. Ini kerana tanpa kehadiran murabbi $\bar{l}$, seseorang itu dibimbangi akan terjerumus ke dalam kesesatan. Oleh itu, semestinya ada bimbingan, hubungan dan keterkaitan yang erat antara murabbī dengan murid kerana murabbī merupakan rujukan terpenting dalam pendidikan spiritual seseorang. ${ }^{21}$

\section{Pembangunan Spiritual}

Tidak dinafikan bahawa hasil kecanggihan teknologi komunikasi dan penyebaran maklumat ketika ini telah banyak memberi kesan kepada masyarakat sama ada positif atau negatif. Dalam konteks hari ini, dapat disaksikan bahawa golongan remaja lebih banyak terdedah kepada impak negatif tersebut dan menjadi mangsa utama. Dalam

19 A. O. Shuriye, "The Spheral Spectrum of Educational Role and Responsibilities of Engineers-Murabbis," Jurnal Usuluddin, Bil. 18 (Disember 2003), 163.

${ }^{20} \mathrm{Al}-\mathrm{Mu}$ 'āyațah, al-Tarbiyah al-Islāmiyyah, 167.

21 M. Akmansyah, "Eksistensi Guru (Mursyid) dalam Pendidikan Spiritual Perspektif Abu Hamid al-Ghazali," al-Tadzkiyyah-Jurnal Pendidikan Islam, Bil. 6. No. 1 (Julai 2015), 320. 
menghadapi cabaran ini, semestinya elemen kawalan diri berteraskan pembangunan spiritual perlu diperkasakan bagi melahirkan remaja yang mempunyai keterampilan dan pegangan diri. Ini kerana aspek keagamaan memainkan peranan yang cukup besar dalam pembangunan spiritual kerana ia dapat membentuk perilaku, tindakan dan keputusan seseorang remaja bertepatan dengan sifat agama sebagai salah satu keperluan spiritual yang sentiasa mendambakan ketengangan dan kebahagiaan. ${ }^{22}$

Secara asasnya, pembangunan spiritual dalam perspektif Islam adalah merujuk kepada pelaksanaan tarbiyah rūhiyyah atau tazkiyah al-nafs. ${ }^{23}$ Ia merupakan suatu proses pendidikan sepanjang hayat yang berbentuk penyucian dalaman dan pembentukan luaran seseorang agar dirinya dapat mengekang kemahuan dan sifat buruk yang membawa kepada ketidaksihatan mental dan kecelaruan mental ${ }^{24}$. Berdasarkan kepada kaedah yang digariskan oleh al-Qur'an, proses pembangunan spiritual ini dapat dilaksanakan melalui beberapa metode yang berikut $^{25}$ :

i. Metode pencegahan dan pengawalan iaitu pengawalan diri dan menghindari diri dari perbuatan buruk dan keji yang wujud dalam individu tersebut.

ii. Metode pengubatan dan rawatan iaitu bagi individu yang melakukan dosa dan berperilaku buruk. Individu ini dianjurkan supaya beristiqamah dalam menjadi manusia yang beriman dan bertaqwa serta menjalankan segala suruhanNya.

${ }^{22}$ Che Zarrina Sa'ari dan Sharifah Basirah Syed Muhsin, "Cadangan Model Psikoterapi Remaja Berasaskan Konsep Tazkiyah al-Nafs," Jurnal Usuluddin, Bil. 36 (Julai-Disember 2012), 49.

${ }^{23}$ Lihat surah al-Baqarah, ayat 151 dan 129.

${ }^{24}$ Abu Dardaa Mohamad et. al., "Konsep Tazkiyah al-Nafs menurut alHarith bin Asad al-Muhasibi," Jurnal Sultan Alauddin Sulaiman Shah, Bil. 4, no. 1 (Jun 2017), 115.

25 Che Zarrina dan Sharifah Basirah, "Cadangan Model Psikoterapi Remaja", 58. 
iii. Metode bimbingan dan pembinaan iaitu suatu usaha pemulihan yang intensif agar terhindar dari dosa serta membina keadaan spiritual dan psikologi yang lebih baik.

Dalam melaksanakan ketiga-tiga metode di atas, metode yang pertama dapat dilaksanakan dengan cara mengawal dan mencegah kerosakan tujuh anggota zahir iaitu pengarahan segala anggota tubuh badan manusia kepada kebaikan dan kebajikan agar ianya menjadi wasīlah mendapatkan pahala yang akan dinilai di akhirat. Bagi metode yang kedua dan ketiga, dapat dilaksanakan menerusi kaedah rawatan dan rehabilitasi sifat-sifat yang dicela dan seterusnya, suntikan penerapan sifat-sifat yang terpuji. $^{26}$

Bagi al-Ghazāli pula, semua proses yang dinyatakan di atas dapat dilaksanakan melalui proses mujāhadah alnafs dan riyādah al-nafs. Mujāhadah al-nafs merupakan suatu usaha yang bersungguh-sungguh melawan nafsu atau mendidiknya. Sementara riyādah al-nafs ialah latihan jiwa ke arah kebaikan dan suatu proses pemindahan daripada sesuatu yang ringan kepada berat secara berperingkatperingkat sehingga mencapai satu keadaan di mana perkara- perkara yang berat menjadi ringan. ${ }^{27}$

Dengan itu, dapatlah difahami bahawa proses pembangunan spiritual merupakan suatu proses pembaikpulihan dan pendisiplinan diri seseorang ke arah yang lebih positif secara dalaman dan luaran menurut acuan agama Islam dengan mengaplikasikan kaedah pembersihan (al-takhallī) dan pembentukan (al-tahallī) sehingga

${ }^{26}$ Che Zarrina Sa'ari et. al., "Terapi Spiritual Melalui Kaedah Tazkiyah al-Nafs oleh Syeikh Abdul Qadir al-Mandili dalam Kitab Penawar Bagi Hati," Jurnal Akidah \& Pemikiran Islam (AFKAR), Bil. 18, Special Issue (Januari 2016), 35.

27 Abū Hāmid Muhammad bin Muhammad al-Ghazalī, Ihyā' 'Ulūm alDīn (Qāhirah: Maktabah Miṣr, 1998), 2:61. 
mencapai tahap al-ihsān dan akhlak kenabian. ${ }^{28}$ Ia sememangnya suatu usaha yang sukar dilaksanakan namun apabila ia menjadi kebiasaan, seseorang itu akan berpegang kepada satu kebiasaan tersebut. Kaedah ini dapat dilaksanakan dengan sentiasa mengutamakan ibadah wajib diikuti dengan sunat kemudian mengekalnya. ${ }^{29}$ Menurut Zakaria Stapa, ${ }^{30}$ semua amalan keislaman yang berbentuk taklif suruhan seperti solat, qiyām al-layl, puasa, tilawah alQur'an dan al-dhikr merupakan sebahagian dari amalan pembersihan jiwa yang semestinya dilaksanakan dalam taraf yang sempurna iaitu satu taraf pelaksanaan dalam bentuk yang sejajar antara amalan lahir dan batin.

Oleh itu, di antara elemen kerohanian yang dapat memenuhi objektif pembangunan spiritual dalam konteks penunaian ibadah seseorang ialah:

i. Al- Iḥsān

Dalam aspek ibadat, iḥsān memberi suatu gambaran tentang seseorang yang melakukan ibadat dalam keadaan penuh sedar ${ }^{31}$ iaitu seseorang meletakkan dirinya di bawah pengawasan Allah SWT dalam setiap masa sehingga timbulnya suatu keyakinan bahawa Dia melihat dirinya seperti sabda Nabi SAW berikut yang bermaksud: ${ }^{32}$

"Bahawa engkau beribadah kepada Allah SWT seolah-olah engkau melihatNya, jika sekiranya

\footnotetext{
${ }^{28}$ Abu Dardaa, "Tazkiyah al-Nafs", 118.

${ }^{29}$ Zidni, "Proses Tazkiyah al-Nafs", 41.

${ }^{30}$ Zakaria Stapa, "Insan Kamil: Ciri dan Proses Pembentukan", Jurnal Akidah \& Pemikiran Islam (AFKAR), Bil. 2, No. 1 (Jun 2001), 54.

31 Sayyid Sābiq, Islāmunā (Qāhirah: Dār al-Fatḥ li I'lām al-'Arabī, 2001), 132.

${ }^{32}$ Abū Bakr al-Jazā'irī, Minhāj al-Muslim (Qāhirah: Dār al-Salām, t.t.), 63.
} 
engkau tidak melihatNya, maka sesungguhnya Dia (Allah) melihat engkau." 33

Berdasarkan kepada pengertian hadis ini, dapatlah difahami bahawa ihssān apabila disertakan dalam setiap ibadah atau rukun-rukun Islam yang lain maka timbul suatu kualiti kerja yang terlaksana dalam taraf yang penuh ikhlas dan tulus secara mutlak tanpa dapat disertakan dengan unsur-unsur seumpama riyā' atau takabbur. ${ }^{34}$ Oleh itu, $i h s \bar{a} n$ merupakan suatu aspek yang dapat menjamin kesempurnaan segala bentuk ibadat sama ada yang fardu atau sunat ke arah pembentukan peribadi dan personaliti seseorang. 35

\section{ii. Mujāhadah al-Nafs}

Dalam konteks ibadat, mujāhadah al-nafs merupakan suatu unsur yang sangat diperlukan kerana sesuatu ibadat benarbenar tidak terlaksana secara ikhlas sekiranya pengertian mujahādah tidak disertakan di dalamnya. ${ }^{36}$ Selain itu, mujāhadah merupakan suatu aspek yang dapat memperbaiki prestasi ibadat seseorang dalam setiap masa dan keadaan seperti yang difahami dalam pernyataan berikut:

"Apabila adanya unsur-unsur kecuaian dalam melakukan ketaatan, maka nafsu itu hendaklah dihukum dan dikeji. Seterusnya kecuaian itu hendaklah diganti pula dengan amalan dan perbuatan yang lain. Apa yang dilakukan ini

${ }^{33}$ Muḥy al-Dīn Abī Zakariyyā bin Sharaf al-Nawāwī, al-Arba ‘̄n alNawawiyyah, Bāb al-Islām wa al-Imān wa al-Iḥsān, (1996), no. hadis 2.

34 Zakaria Stapa, Akhlak dan Tasawwuf Islam (Kuala Lumpur: Berita Publishing Sdn. Bhd, 1995), 14.

35 'Alī 'Abd al-Halīm Mạ̣mūd, Wasā'il al-Tarbiyyah 'ind al-Ikhwān alMuslimīn (Qāhirah: Dār al-Tawzī' wa al-Nashr al-Islāmiyyah, 1991), 149.

${ }^{36}$ Zakaria, Akhlak, 59. 
merupakan suatu bentuk asuhan sehingga jiwa menjadi tenang, bersih dan baik." ${ }^{37}$

Berdasarkan catatan ini, maka mujāhadah al-nafs hendaklah dilaksanakan oleh seseorang bagi memantapkan keimanan kepada Allah SWT, melaksanakan segala bentuk kewajipan berdasarkan tuntutan waktu serta melaksanakan segala ibadat sunat (nawāfil) berdasarkan tuntutan diri sendiri. $^{38}$

\section{iii.Istiqāmah}

Istiqāmah merupakan suatu elemen yang dapat memastikan keberhasilan proses pembangunan spiritual secara berterusan melalui pelaksanaan amalan taklif berbentuk suruhan dan larangan. Ini kerana faktor kecelaan perbuatan seseorang adalah berpunca dari jiwa dan hati yang tidak terbangun dengan sempurna. Keadaan ini merupakan akibat langsung dari hati yang tidak istiqāmah dalam melawan hasutan hawa nafsu dan syaitan sehingga mengakibatkan hatinya dikuasai oleh nafs al-ammārah. ${ }^{39}$ Dari sini, timbulnya suatu keperluan dan kemestian agar seseorang itu berusaha untuk mengadakan dawrah spiritual bagi mempertingkatkan kualiti spiritualnya di setiap masa. $^{40}$

Dengan terlaksananya ketiga-tiga elemen yang dinyatakan di atas, maka diharapkan setiap ibadat yang dilaksanakan oleh seseorang individu akan berperanan

${ }^{37}$ Abū Bakr al-Jazā'irī, Minhaj al-Muslim (Qāhirah: Dār al-Salām, t.t.), 65.

38 Sa‘id Hawwā, Tarbiyatunā al-Rūḥiyyah (Qāhirah: Dār al-Salām, 1997), 120.

${ }^{39}$ Norfadilah et.al., "Pembangunan Kerohanian Berasaskan al-Muhasibi Dalam Menangani Gejala Sosial Masa Kini”, e-Proceeding of the International Conference of Integration Knowledge (Bandung: World Conference.net., 2014), 88.

${ }^{40}$ Sa'id Hawwā, Tarbiyatunā, 98. 
Mohd Suhari \& Mohd Farid, "Pembangunan Spiritual dalam Pelaksanaan Program Tarbih," Afkār Vol. 20 Issue 2 (2018): 127-158

sebagai mekanisme pembangunan spiritual $^{41}$ seperti berikut:

Jadual 1: Wasilah Pembangunan Spiritual

\begin{tabular}{|c|l|l|}
\hline Bil. & Kotoran-Kotoran Jiwa & $\begin{array}{l}\text { Wasilah Pembangunan } \\
\text { Spiritual }\end{array}$ \\
\hline 1. & $\begin{array}{l}\text { Takabbur, sombong } \\
\text { dan 'ujub }\end{array}$ & Solat, Tauhid dan tafakur \\
\hline 2. & $\begin{array}{l}\text { Syahwat perut dan } \\
\text { kemaluan }\end{array}$ & Puasa dan nikah \\
\hline 3. & Bencana lisan & $\begin{array}{l}\text { Zikrullah, tafakkur, } \\
\text { muhasabah, dan muraqabah, } \\
\text { mujahadah dangati } \\
\text { mati }\end{array}$ \\
\hline 4. & $\begin{array}{l}\text { Marah, dengki dan iri } \\
\text { hati }\end{array}$ & $\begin{array}{l}\text { Tilawah al-Qur'an, sabar dan } \\
\text { syukur, memaafkan dan kasih } \\
\text { sayang }\end{array}$ \\
\hline 5. & Cinta harta dan kikir & Zakat, infaq dan zuhud \\
\hline
\end{tabular}

Sumber: Hayu A'la Aslami, 2016

\section{Permasalahan Kajian}

Berlandaskan matlamat pendidikan Islam dalam membangunkan sahsiah pelajar yang soleh, maka terdapatnya keperluan yang mendesak untuk mempertingkatkan kualiti kerohanian pelajar dalam konteks pendidikan bersepadu masa kini. Ini kerana seseorang yang tampil dengan akhlak serta peribadi yang mulia adalah lahir daripada jiwa yang bersih dan rohani yang suci.

Berdasarkan kajian-kajian yang terdahulu, pelaksanaan jenis program sahsiah di sekolah-sekolah di Malaysia turut menyumbang ke arah penerapan nilai-nilai murni serta meningkatkan prestasi kurikulum dan

41 Hayu A'la Aslami, Konsep Tazkiyatun Nafs dalam Kitab 'Ihyā 'Ulumuddin Karya Imam al-Ghazali (Disertasi Sarjana, Fakultas Tarbiyah dan Ilmu Keguruan, Institut Agama Islam Negeri, 2016), 62. 
kokurikulum dalam kalangan pelajar. ${ }^{42}$ Kajian terdahulu juga berpendapat kebanyakan pelajar bersedia dan berminat untuk mengikuti aktiviti khususnya yang bercorak kerohanian di sekolah dan kebanyakan mereka menyedari akan pentingnya elemen kerohanian dalam setiap aktiviti yang mereka sertai bagi melahirkan peribadi yang mempunyai akhlak yang mulia. ${ }^{43}$

Dalam masa yang sama, terdapatnya suatu keperluan yang mendesak untuk melahirkan guru pendidikan Islam yang cemerlang dalam usaha meningkatkan modal insan cemerlang secara berterusan menerusi aspek pembangunan kerohanian pelajar. ${ }^{44}$ Selain itu, terdapat juga hasil kajian yang menjelaskan bahawa guru bukanlah sebagai robot atau pun alat untuk menyampaikan ilmu sahaja malah mereka berperanan untuk menanam nilai-nilai murni bagi menghidupkan potensi-potensi dalaman dan luaran dalam diri murid supaya dapat berkembang dengan sebaiknya. ${ }^{45}$ Berdasarkan dapatan-dapatan kajian terdahulu, amatlah nyata bahawa matlamat membangunkan aspek kerohanian pelajar merupakan suatu keutamaan yang perlu dipertimbangkan dalam rangka menterjemahkan kehendak dan matlamat falsafah Pendidikan Kebangsaan masa kini.

Oleh itu, antara permasalahan utama yang mendasari kajian ini ialah meskipun program tarbiah dapat

42 Norsidah Ahmad et.al., "Pelaksanaan Program Kecemerlangan Pembangunan Sahsiah Sekolah-Sekolah di Malaysia," International Journal of Religion Research in Education, Bil. 2, No. 1 (Julai 2017), 105.

${ }^{43}$ Nik Safiah Nik Abdullah et.al., "Kepentingan Elemen Kerohanian dalam Pelaksanaan Aktiviti MRSM Ulul Albab: Kajian Kes di MRSM Gemencheh, Negeri Sembilan," Journal of Global Business and Social Entrepreneurship, Bil. 2, No. 1 (Jun 2015), 79.

${ }^{44}$ Kamarul Azmi b. Jasmi, Guru Pendidikan Islam Sekolah Menengah di Malaysia: Satu Kajian Kes (Tesis Ph.D., Universiti Kebangsaan Malaysia, 2010).

${ }^{45}$ Rohana Hamzah et.al, "Pembangunan Jiwa Pendidik Dalam Kalangan Bakal Pendidik", Jurnal Teknologi (Social Sciences), Bil. 61, No. 1 (Julai 2012), 31. 
dilaksanakan secara berterusan dalam kalangan pelajar asrama di SMKA Pulau Pinang, namun elemen-elemen pembangunan spiritual seperti amalan mujāhadah al-nafs dan al-ihsān masih tidak dapat diterapkan sepenuhnya dalam amalan seharian pelajar di asrama. Aspek yang dinyatakan ini memperlihatkan sebahagian besar pelajar yang tinggal di asrama masih tidak mencapai tahap yang konsisten (istiqāmah) dalam penunaian sesetengah ibadat fardu dan sunat sebagai wasilah pembangunan spiritual sekiranya dinilai dari sudut kemenjadian sebenar seseorang pelajar seperti yang dihasratkan dalam Modul Pembangunan Murid Asrama (MPMA). ${ }^{46}$

Apa yang dapat dirumuskan ialah ketiadaan guru yang benar-benar dapat menjalankan tugas sebagai murabbī dan mursyid merupakan di antara faktor utama ketidakberkesanan pelaksanaan program tarbiah dalam menerapkan elemen-elemen kerohanian sebagai manhaj tarbiyah rühiyyah sedangkan menurut perspektif al-Quran, peranan utama murabbī adalah melaksanakan tugas-tugas al-tazkiyah iaitu membersih dan meninggikan jiwa manusia selaras dengan kehendak pencipta-Nya. Aspek yang diperkatakan ini adalah selari dengan garis panduan yang telah dikeluarkan oleh Kementerian Pelajaran Malaysia (2007) iaitu ${ }^{47}$ :

"Setiap warden asrama adalah bertanggungjawab untuk memantau serta merekodkan aktiviti-aktiviti harian dan berkala seperti waktu solat dan kelas agama yang dianjurkan di asrama."

\footnotetext{
${ }^{46}$ Kementerian Pelajaran Malaysia, Modul Pembangunan Murid Asrama (MPMA) (Putrajaya: Bahagian Sekolah, Kementerian Pelajaran Malaysia, 2007), 11.

47 Kementerian Pelajaran Malaysia, Hal Ehwal Murid (1969-2003) (Shah Alam: Giga Wise Network Sdn. Bhd., t.t.), 183.
} 


\section{Metodologi Kajian}

Kajian ini berbentuk kajian penerokaan (exploratory research) yang menggabungkan pendekatan kajian kualitatif dan kuantitatif iaitu pengumpulan data dilaksanakan melalui kaedah pemerhatian, temubual dan soal selidik sebagai kaedah triangulasi bagi pengukuhan dapatan kajian. Oleh itu, proses pengumpulan data melalui ketiga-dua instrumen ini dapat dijelaskan seperti yang berikut:

\section{i. Pemerhatian}

Dalam proses pengumpulan data melalui kaedah pemerhatian, ${ }^{48}$ penyelidik telah merekod data-data pemerhatian berpandukan senarai pembolehubah yang telah dikenal pasti. Dalam aspek ini, permasalahan kajian atau soalan-soalan kajian telah menentukan apa yang perlu diperhatikan oleh penyelidik. Oleh itu, data-data pemerhatian direkodkan dalam bentuk deskriptif iaitu tingkah laku responden dihuraikan dengan perkataan bagi menerangkan sesuatu fenomena kajian yang sedang berlaku.

\section{ii. Temubual}

Secara khusus, kaedah temubual dijalankan oleh penyelidik sebagai asas penting untuk memahami fenomena yang dikaji dalam konteks kajian kualitatif. ${ }^{49}$ Bagi memenuhi objektif ini, penyelidik telah memilih seramai 15 orang responden berdasarkan persampelan bertujuan (purposive sampling) dan proses temu bual dilaksanakan secara bersemuka (face to face) berdasarkan tarikh dan masa temu bual yang telah dipersetujui. Segala jawapan yang telah diberikan oleh responden direkodkan sepenuhnya oleh penyelidik dan dibuat transkripsi secara berperingkat.

${ }^{48}$ Othman Lebar, Penyelidikan Kualitatif: Pengenalan kepada Teori dan Metod (Tanjong Malim: Universiti Pendidikan Sultan Idris, 2009), 60.

49 Sabitha Marican, Penyelidikan Sains Sosial: Pendekatan Pragmatik (Batu Caves: Edusystem Sdn. Bhd., 2009), 68. 


\section{iii. Soal Selidik}

Objektif terpenting penyelidik menggunakan soal selidik adalah kerana ia lebih praktikal untuk memungut data dalam populasi kajian yang besar. Bagi tujuan ini, penyelidik telah mengambil saiz sampel sebanyak 30 peratus dari jumlah keseluruhan populasi iaitu seramai 509 orang responden melalui persampelan rawak berlapis berdasarkan saranan penyelidik terdahulu. ${ }^{50}$

\section{Objektif Kajian}

Secara khusus, kajian ini adalah untuk memenuhi objektifobjektif kajian berikut:

1. Untuk mengenalpasti elemen-elemen pembangunan spiritual dalam pelaksanaan program tarbiah di asrama SMKA Pulau Pinang.

2. Untuk menilai tahap penglibatan guru asrama sebagai murabbī dalam pembangunan spiritual pelajar di asrama SMKA Pulau Pinang.

3. Untuk menilai keberkesanan program tarbiah dalam aspek pembangunan spiritual pelajar di asrama SMKA Pulau Pinang.

\section{Analisis Dapatan Kajian}

Analisis data boleh difahami sebagai proses menghuraikan masalah kajian berasaskan persoalan kajian (research questions) dengan tujuan menjelaskan objektif yang telah dinyatakan. Dalam konteks ini, analisis data kajian ini dibahagikan kepada dua bahagian yang berikut:

\section{Analisis Kualitatif}

i. Amalan solat fardu Subuh berjemaah

Dapatan kajian pemerhatian menunjukkan amalan penunaian solat fardu Subuh adalah terlaksana sepenuhnya dalam kalangan responden berdasarkan aspek pergerakan pelajar ke surau semasa waktu Fajr dan amalan penunaian

50 Uma Sekaran, Research Methods for Business: A Skill-Building (United States of American, John Wiley \& Son, Inc., 2009), 117. 
solat sunat Fajr. Walau bagaimanapun, elemen spiritual iaitu amalan mujāhadah al-nafs hanya dapat dihayati dalam sebahagian kecil responden sahaja berdasarkan bilangan responden yang hadir semasa penunaian solat subuh berjemaah di asrama pada hari minggu. Dalam masa yang sama, penglibatan warden asrama sebagai murabbi dilihat berada di tahap yang sangat minimum.

Di antara data pemerhatian (2016) yang dapat menjelaskan keadaan ini adalah seperti yang berikut:

SEK D: SS (5)

Masuk waktu Subuh jam 5.49 pagi. Pelajarpelajar mula bergerak pada jam 5.55 pagi. Terdapat lebih kurang 1-6 orang pelajar yang berada di surau. Pelajar azan lebih kurang jam 5.58 pagi. Terdapat 8 orang pelajar lelaki dan 2 orang pelajar perempuan yang mendirikan solat sunat qabliyyah Subuh. Kelihatan bilangan pelajar lelaki lebih ramai dari pelajar perempuan sebelum solat Subuh. Didapati tidak terdapat warden bertugas yang solat Subuh berjemaah dengan pelajar.

Dapatan pemerhatian ini adalah selari dengan jawapan responden melalui kajian temubual (2016) yang berikut:

Responden 11(GL 11):

"Kalau solat Subuh itu... adalah dalam satu saf atau satu saf setengah pada waktu solat Subuh dan itu sahaja yang ada. Kemudian solat Zuhur, Asar, Maghrib dan Isya' itu alhamdulillah."

ii. Amalan qiyām al-layl

Dapatan kajian pemerhatian menunjukkan amalan qiyām al-layl terlaksana secara konsisten dalam sebahagian kecil pelajar asrama sahaja. Berikutan itu, dapat difahami bahawa penghayatan mujāhadah al-nafs dan al-ihsān melalui amalan ini hanya berlaku dalam sebahagian kecil responden sahaja. Dapatan ini juga menunjukkan betapa perlu penyertaan murabbī sebagai pembimbing kepada 
responden dalam pelaksanaan amalan näfilah ini. Di antara data pemerhatian (2016) yang dapat menjelaskan keadaan ini adalah seperti berikut:

SEK B: PQ (1)

Hanya pelajar yang terlibat. Warden tidak terlibat. Jam 4.30 pagi loceng ditekan. Tidak berlaku pergerakan pelajar secara serentak. Pelajar bersiap untuk mengerjakan qiamullail pada jam 5.00 pagi. Pelajar melaksanakan qiamullail dengan mengerjakan solat tahajjud sebanyak 2 rakaat. Seterusnya pelajar melaksanakan solat sunat hajat. Pelajar membaca doa. Pelajar mengakhiri qiamullail dengan mengerjakan solat sunat witr. Pelaksanaan qiamullail memperlihatkan pelajar bersemangat dan berminat. Observasi tamat pada jam 5.45 pagi.

Dapatan pemerhatian ini selari dengan kajian temubual iaitu:

Responden 12 (GL 12):

"Dari apa yang saya perhatikan... bilangan pelajar tingkatan 2 itu ada dalam 41 orang pelajar, tetapi yang hadir melibatkan diri dalam program tersebut hanya dalam $40 \%$ hingga $50 \%$ sahaja, dan yang tidak hadirnya ramai di asrama."

iii. Tilawah al-Qur'an

Dapatan pemerhatian menunjukkan amalan tilawah alQur'an adalah terlaksana dalam kalangan responden dalam tiga waktu utama iaitu selepas solat Asar, Maghrib dan Isya'. Walau bagaimanapun, elemen kerohanian (spiritual) seperti tadabbur dan ta'athur sebagai dimensi dalaman amalan ini kelihatan kurang dipraktikkan dalam kalangan responden. Dapatan ini adalah berdasarkan data pemerhatian berikut:

SEK A: TQ (1) 
"Semua pelajar telah berada di dalam surau selepas menunaikan solat Isya'. Tepat pada jam 10.35 malam, semua pelajar mula bertadarrus dan ramai yang memberikan kerjasama. Pelajar tingkatan 5 telah mengetuai bacaan tadarus. Surah yang dibaca ialah surah al-Mulk. Segelintir pelajar masih menunaikan solat Isya' semasa pelajar yang lain sedang bertadarus. Tiada warden dan pelajar yang memberi teguran. Semua pelajar balik ke dorm masingmasing pada pukul 10.45 malam".

Dapatan pemerhatian ini adalah selari dengan jawapan responden melalui kajian temubual berikut:

Responden 9 (ML9):

"Setakat ini para pelajar asrama SMKA, ana lihat masih kurang kerana tiada bimbingan... tidak ada pembimbing untuk membimbing para pelajar mentafsir satu-satu ayat."

iv. Amalan zikir

Dapatan kajian pemerhatian menunjukkan amalan membaca zikir Ma'thūrāt sebagai zikir harian pelajar terlaksana di setiap asrama SMKA Pulau Pinang dalam tiga waktu yang berbeza iaitu selepas solat Subuh, Asar dan sebelum solat Maghrib. Sekali pun amalan ini terlaksana. Namun penghayatan adab-adab zikir ini masih perlu dipertingkatkan dalam kalangan responden. Dapatan ini adalah berdasarkan data pemerhatian berikut:

SEK B: BM(4)

(Sekitar jam 6.15 petang).. loceng dibunyikan dan pelajar turun ke bawah. Pakaian pelajar adalah bebas. Bacaan Ma'thūrāt diketuai oleh pelajar tingkatan 5. Pelajar duduk secara rawak di dalam dewan. Setiap pelajar ada (teks) Ma'thūrāt. Pelajar membaca Ma'thūrāt pendek (ringkas). Ada pelajar yang lewat. Bacaan 
Ma'thūrāt tamat pada jam 6.35 malam, tutup majlis dan pelajar makan malam.

v. Puasa sunat

Dapatan keseluruhan kajian pemerhatian menunjukkan amalan ini terlaksana secara rutin dalam sebilangan kecil pelajar asrama di SMKA Pulau Pinang pada setiap hari Isnin dan Khamis. Oleh itu, objektif untuk melatih para pelajar asrama dalam konteks menguasai diri (mujāhadah al-nafs) sebagai elemen pembangunan kerohanian kelihatan tercapai dalam sebilangan kecil responden sahaja. Dapatan ini adalah berdasarkan data pemerhatian berikut:

SEK D: PS (1)

Terdapat seramai 10 orang pelajar tingkatan 5 yang berpuasa sunat. Manakala anggaran pelajar tingkatan 1,2 dan 3 yang berpuasa sunat adalah seramai 19 orang. Anggaran keseluruhan pelajar yang berpuasa sunat adalah seramai 42 orang.

Dapatan pemerhatian ini adalah selari dengan kajian temubual (2016) yang berikut:

Responden 14 (GP 14):

"Apa yang saya lihat, ia tidak berjalan dalam melibatkan jumlah bilangan pelajar besar dan hanya segelintir pelajar sahaja yang dapat istiqamah dalam melaksanakan puasa sunat ini pada hari Isnin dan Khamis." 
Mohd Suhari \& Mohd Farid, "Pembangunan Spiritual dalam Pelaksanaan Program Tarbih,” Afkār Vol. 20 Issue 2 (2018): 127-158

\section{Analisis data kuantitatif}

Jadual 2: Statistik Deskriptif Guru Asrama Sebagai Murabbī

\begin{tabular}{|c|c|c|c|c|c|c|c|c|c|c|}
\hline Item & Pernyataan & AS & $\mathrm{s}$ & TP & TS & ATS & $\begin{array}{l}\text { N .Res } \\
=477\end{array}$ & Min & S.P. & Interpretasi \\
\hline 1. & $\begin{array}{lr}\text { Warden } & \text { asrama } \\
\text { memainkan peranan } \\
\text { yang paling penting } \\
\text { dalam pelaksanaan } \\
\text { program tarbiah di } \\
\text { asrama. }\end{array}$ & $\begin{array}{l}170 \\
35.6 \%\end{array}$ & $\begin{array}{l}159 \\
33.3 \%\end{array}$ & $\begin{array}{l}96 \\
20.1 \%\end{array}$ & $\begin{array}{l}31 \\
6.5 \%\end{array}$ & $\begin{array}{l}20 \\
4.2 \%\end{array}$ & $\begin{array}{l}476 \\
99.8 \%\end{array}$ & 3.90 & 1.09 & $\begin{array}{c}\text { Sederhana } \\
\text { Tinggi }\end{array}$ \\
\hline 2. & $\begin{array}{l}\text { Warden asrama kurang } \\
\text { melibatkan diri } \\
\text { bersama-sama dengan } \\
\text { pelajar asrama dalam } \\
\text { setiap program tarbiah } \\
\text { di asrama. }\end{array}$ & $\begin{array}{l}53 \\
11.1 \%\end{array}$ & $\begin{array}{l}118 \\
24.7 \%\end{array}$ & $\begin{array}{l}123 \\
25.8 \%\end{array}$ & $\begin{array}{l}118 \\
24.7 \%\end{array}$ & $\begin{array}{l}65 \\
13.6 \%\end{array}$ & $\begin{array}{l}477 \\
100 \%\end{array}$ & 3.05 & 1.22 & $\begin{array}{c}\text { Sederhana } \\
\text { Tinggi }\end{array}$ \\
\hline 3. & $\begin{array}{lr}\text { Warden } & \text { asrama } \\
\text { menjadi contoh yang } \\
\text { terbaik } \\
\text { pelaksanaan dalam } \\
\text { program tarbiah di } \\
\text { asrama. }\end{array}$ & $\begin{array}{l}134 \\
28.1 \%\end{array}$ & $\begin{array}{l}145 \\
30.4 \%\end{array}$ & $\begin{array}{l}135 \\
28.3 \%\end{array}$ & $\begin{array}{l}39 \\
8.2 \%\end{array}$ & $\begin{array}{l}23 \\
4.8 \%\end{array}$ & $\begin{array}{l}476 \\
99.8 \%\end{array}$ & 3.69 & 1.11 & $\begin{array}{c}\text { Sederhana } \\
\text { Tinggi }\end{array}$ \\
\hline 4. & $\begin{array}{l}\text { Tidak semua warden } \\
\text { asrama mempunyai } \\
\text { kefahaman Islam yang } \\
\text { jelas dalam pelaksanaan } \\
\text { setiap program tarbiah } \\
\text { di asrama. }\end{array}$ & $\begin{array}{l}66 \\
13.8 \%\end{array}$ & $\begin{array}{l}130 \\
27.3 \%\end{array}$ & $\begin{array}{l}155 \\
32.5 \%\end{array}$ & $\begin{array}{l}75 \\
15.7 \%\end{array}$ & $\begin{array}{l}51 \\
10.7 \%\end{array}$ & $\begin{array}{l}477 \\
100 \%\end{array}$ & 2.82 & 1.16 & $\begin{array}{l}\text { Sederhana } \\
\text { rendah }\end{array}$ \\
\hline 5. & $\begin{array}{lr}\text { Ketua warden } & \text { asrama } \\
\text { bertindak } & \text { sebagai } \\
\text { penggerak rama } & \text { utama } \\
\text { pelaksanaan program } \\
\text { tarbiah di asrama. }\end{array}$ & $\begin{array}{l}221 \\
46.3 \%\end{array}$ & $\begin{array}{l}130 \\
27.3 \%\end{array}$ & $\begin{array}{l}87 \\
18.2 \%\end{array}$ & $\begin{array}{l}24 \\
5.0 \%\end{array}$ & $\begin{array}{l}15 \\
3.1 \%\end{array}$ & $\begin{array}{l}477 \\
100 \%\end{array}$ & 4.09 & 1.06 & Tinggi \\
\hline \multicolumn{8}{|c|}{ Min keseluruhan } & 3.51 & 3.78 & $\begin{array}{c}\text { Sederhana } \\
\text { Tinggi }\end{array}$ \\
\hline
\end{tabular}

Sumber: Soal selidik tahun 2016

Jadual 2 di atas menunjukkan penilaian responden tentang warden asrama sebagai murabbī di asrama. Min keseluruhan bagi lima item bahagian ini berada pada tahap penilaian sederhana tinggi iaitu 3.51 dan sisihan piawai ialah 3.78. Berdasarkan dapatan yang diperolehi, didapati responden memberi penilaian tinggi pada item yang kelima sahaja iaitu ketua warden asrama bertindak sebagai 
penggerak utama pelaksanaan program tarbiah di asrama dengan skor min 4.09, sisihan piawai 1.06.

Manakala bagi item ke empat iaitu tidak ke semua warden asrama mempunyai kefahaman Islam yang jelas dalam pelaksanaan program tarbiah di asrama berada pada tahap penilaian sederhana rendah dengan skor min 2.82 dan sisihan piawai 1.16. Sementara item-item yang pertama, kedua dan ketiga pula berada pada tahap penilaian sederhana tinggi iaitu skor min sebanyak 3.90, 3.05, 3.69 dan sisihan piawai sebanyak 1.09, 1.22, 1.11.

Jadual 3: Manhaj Pembangunan Spiritual dalam Program Tarbiah

\begin{tabular}{|c|c|c|c|c|c|c|c|c|c|c|}
\hline BIL. & PERNYATAAN & AS & $S$ & TP & TS & ATS & $\begin{array}{l}\text { N. RES } \\
=477\end{array}$ & MIN & S.P. & NILAI MIIN \\
\hline 1. & $\begin{array}{l}\text { Pelajar - pelajar asrama } \\
\text { tidak diberi kefahaman } \\
\text { tentang maksud "merasai } \\
\text { kehadiran Allah S.W.T " } \\
\text { dalam pelaksanaan ibadat } \\
\text { fardu dan sunat di asrama. }\end{array}$ & $\begin{array}{c}25 \\
5.2 \%\end{array}$ & $\begin{array}{c}51 \\
10.7 \%\end{array}$ & $\begin{array}{c}83 \\
17.4\end{array}$ & $\begin{array}{l}128 \\
26.8\end{array}$ & $\begin{array}{l}190 \\
39.8\end{array}$ & $\begin{array}{c}477 \\
100 \%\end{array}$ & 3.85 & 1.21 & $\begin{array}{c}\text { Sederhana } \\
\text { Tinggi }\end{array}$ \\
\hline 2. & $\begin{array}{l}\text { Pelajar - pelajar asrama } \\
\text { diberi kefahaman tentang } \\
\text { maksud " melawan hawa } \\
\text { nafsu" dalam pelaksanaan } \\
\text { ibadat fardu dan sunat di } \\
\text { asrama. }\end{array}$ & $\begin{array}{l}210 \\
44.0\end{array}$ & $\begin{array}{l}169 \\
35.4\end{array}$ & $\begin{array}{c}65 \\
13.6\end{array}$ & $\begin{array}{l}21 \\
4.4\end{array}$ & $\begin{array}{l}11 \\
2.3\end{array}$ & $\begin{array}{c}476 \\
99.8 \%\end{array}$ & 4.15 & 0.97 & Tinggi \\
\hline 3. & $\begin{array}{l}\text { Pelajar - pelajar asrama } \\
\text { tidak diberi kefahaman } \\
\text { tentang maksud " } \\
\text { pembersihan jiwa " dalam } \\
\text { pelaksanaan ibadat fardu } \\
\text { dan sunat di asrama. }\end{array}$ & $\begin{array}{c}37 \\
7.8 \%\end{array}$ & $\begin{array}{c}53 \\
11.1 \%\end{array}$ & $\begin{array}{c}78 \\
16.4\end{array}$ & $\begin{array}{l}133 \\
27.9\end{array}$ & $\begin{array}{l}176 \\
36.9\end{array}$ & $\begin{array}{c}477 \\
100 \%\end{array}$ & 3.75 & 1.27 & $\begin{array}{c}\text { Sederhana } \\
\text { Tinggi }\end{array}$ \\
\hline 4. & $\begin{array}{l}\text { Program tarbiah dapat } \\
\text { dilaksanakan secara } \\
\text { berterusan sepanjang tahun. }\end{array}$ & $\begin{array}{l}222 \\
46.5\end{array}$ & $\begin{array}{l}134 \\
28.1\end{array}$ & $\begin{array}{c}88 \\
18.4\end{array}$ & $\begin{array}{l}17 \\
3.6\end{array}$ & $\begin{array}{l}15 \\
3.1\end{array}$ & $\begin{array}{c}476 \\
99.8 \%\end{array}$ & 4.12 & 1.03 & Tinggi \\
\hline \multicolumn{8}{|c|}{ Min Keseluruhan } & 3.96 & 3.18 & $\begin{array}{c}\text { Sederhana } \\
\text { Tinggi }\end{array}$ \\
\hline
\end{tabular}

Sumber: Soal selidik tahun 2016 
Jadual 3 di atas menunjukkan penilaian responden berkenaan manhaj pelaksanaan program tarbiah di asrama yang melibatkan empat item. Min keseluruhan bagi empat item ini berada pada tahap penilaian sederhana tinggi iaitu 3.96 dan sisihan piawai ialah 3.18. Berdasarkan dapatan yang diperolehi didapati bahawa responden memberi penilaian yang tinggi hanya pada item kedua dan keempat dengan skor min 4.15, 4.12 dan sisihan piawai 0.97, 1.03. Manakala bagi item pertama dan ketiga, responden memberi penilaian pada tahap sederhana tinggi dengan skor min 3.85, 3.75 dan sisihan piawai 1.21, 1.27.

\section{Jadual 4: Kesan Pelaksanaan Program Tarbiah Dalam Aspek Pembangunan Spiritual}

\begin{tabular}{cccccccc}
\hline Bil. & Tempoh & N.Res. & Min & S.Piawai & F & d.f. & Sig. \\
\hline 1. & $1-2$ tahun & 250 & 44.97 & 7.03 & & & \\
2. & $3-4$ tahun & 150 & 45.27 & 7.20 & & & \\
3. & $5-6$ tahun & 77 & 46.18 & 6.76 & 0.87 & 2 & 0.42 \\
& Jumlah & $\mathbf{4 7 7}$ & $\mathbf{4 5 . 2 6}$ & $\mathbf{7 . 0 4}$ & & & \\
\hline \multicolumn{7}{c}{}
\end{tabular}

Sumber: Soal selidik tahun 2016

Jadual 4 di atas menunjukkan dapatan keseluruhan perbezaan min di antara tempoh masa responden tinggal di asrama berdasarkan ujian ANOVA sehala dalam aspek kesan pelaksanaan program tarbiah di asrama terhadap pembangunan spiritual pelajar asrama di SMKA Pulau Pinang. Secara keseluruhannya, tidak terdapat perbezaan yang signifikan $(F=0.87, d f=2, p=0.42$ iaitu $p>0.05)$ di antara tempoh masa responden tinggal di asrama dalam aspek; kesan pelaksanaan tarbiah terhadap pembangunan spiritual pelajar asrama di SMKA Pulau Pinang.

\section{Kesimpulan dan Saranan}

Dapatan kajian secara keseluruhannya menunjukkan elemen pembangunan spiritual iaitu mujāhadah al-nafs dan al-ihsān masih tidak dapat diterapkan sepenuhnya dalam konteks pelaksanaan program tarbiah rūhiyyah di asrama 
SMKA Pulau Pinang. Dalam pelaksanaan solat Subuh berjemaah, didapati tidak semua responden yang mampu konsisten dalam penunaian solat fardu berjemaah di asrama pada hari minggu. Begitu juga, amalan qiyām al-layl sebagai ibadat náfilah yang utama, didapati objektif untuk melatih pelajar bermujahadah dan beribadah pada waktu malam tidak tercapai sepenuhnya dalam kebanyakan responden bagi mempertingkatkan kualiti spiritual mereka.

Oleh itu, jelaslah aspek mujāhadah perlu dipertingkatkan dalam manhaj tarbiah rühiyyah melalui penunaian ibadat fardu dan sunat dalam kalangan responden memandangkan kajian terdahulu telah menunjukkan bahawa amalan keagamaan yang dilaksanakan secara konsisten dapat mencegah pelajar daripada tingkah laku berisiko. ${ }^{51}$

Bagi amalan tilawah al-Qur'an dan zikir pula, sekali pun kedua-dua amalan ini terlaksana oleh sebahagian besar responden, namun elemen-elemen dalaman (dimensi batin) iaitu tadabbur dan ta'athur tidak berlaku sepenuhnya seperti yang disarankan oleh kajian terdahulu iaitu amalan keagamaan seperti membaca al-Qur'an merupakan suatu bentuk program keagamaan yang dapat meningkatkan disiplin pelajar di sekolah. $^{52}$ Akhirnya, pelaksanaan amalan puasa sunat sebagai wasīlah pembangunan spiritual, didapati objektif pembangunan spiritual melalui amalan ini kelihatan tidak tercapai sepenuhnya dalam keseluruhan responden iaitu untuk melatih pelajar yang dapat menguasai diri. Ini kerana terdapat sebahagian kecil sahaja pelajar asrama yang sanggup dan mampu

${ }^{51}$ Azlina Abu Bakar, "Pembinaan Model Kesejahteraan Diri Remaja di Terengganu” (Tesis Ph.D, Fakulti Pendidikan, Universiti Malaya, 2011).

${ }^{52}$ Ishak bin Ismail, "Budaya Nilai- Nilai Keagamaan dan Disiplin Pelajar di Sekolah Menengah Agama Negeri Selangor Darul Ehsan” (Tesis Ph.D, Fakulti Pendidikan, Universiti Kebangsaan Malaysia, 2012). 
melibatkan diri dalam pelaksanaan amalan ini secara sukarela di asrama setiap minggu.

Dengan ini, dapatan keseluruhan kajian kualitatif dan kuantitatif menunjukkan hasil kajian yang sama iaitu elemen pembangunan spiritual dalam pelaksanaan program tarbiah rūhiyyah di asrama SMKA Pulau Pinang masih tidak dapat diterapkan sepenuhnya bagi membangunkan kualiti spiritual pelajar. Kajian ini turut mendedahkan bahawa penglibatan dan penyertaan guru asrama sebagai murabbī dalam pelaksanaan program tarbiah masih berada di tahap yang rendah dalam rangka merealisasikan objektif pembangunan spiritual iaitu pembentukan sahsiah pelajar di asrama SMKA. Implikasinya ialah pelaksanaan program tarbiah di asrama tidak memberi kesan yang ketara terhadap pembangunan spiritual pelajar sekali pun program tarbiah telah lama dilaksanakan dan lamanya mereka berada di asrama.

Akhirnya, kajian ini menyarankan bahawa pembangunan spiritual dalam pelaksanaan program tarbiah di asrama SMKA Pulau Pinang seharusnya mempertingkatkan elemen mujāhadah al-nafs dan al-iḥsān sebagai manhaj tarbiah rühiyyah bagi merealisasikan objektif pembangunan spiritual pelajar iaitu pembentukan sahsiah pelajar. Untuk itu, kajian ingin menyarankan bahawa guru-guru asrama seharusnya berperanan sebagai murabbi dan murshid dalam konteks pembangunan spiritual pelajar di asrama SMKA Pulau Pinang.

\section{Rujukan}

A. O. Shuriye. "The Spheral Spectrum of Educational Role and Responsibilities of Engineers-Murabbis". Jurnal Usuluddin. Bil. 18, Disember 2003.

Abu Dardaa Mohamad et. al. "Konsep Tazkiyah al-Nafs Menurut al-Harith bin Asad al-Muhasibi". Jurnal Sultan Alauddin Sulaiman Shah. Bil. 4, no. 1, Jun 2017. 
'Abd al-'Azīz, Fu'ad. Al-Mu'allim al-Awwal: Qudwah likulli Mu'allim wa Mu'allimah. Riyāḍ: Dār al-Qāsim, 1997.

Al-Ghazāli, Abū Hāāmid Muḥammad bin Muhammad. Ihyyā' 'Ulūm al-Dīn. Qāhirah: Maktabah Misr, 1998.

Al-Jazā'irī, Abū Bakr. Minhāj al-Muslim. Qāhirah: Dār alSalām, t.t.

Al-Mu'āyațah, 'Abd al-'Azīz. Al-Madkhal ilā Usūl alTarbiyyah al-Islāmiyyah. Qāhirah: Dār al-Tawzī' wa alNashr al-Islāmiyyah, 2002.

Al-Ṭabārī. Tafsīr al-Ṭabarī. Beirūt: Dār al-Kutub al'Ilmiyyah, 1992.

Al-Ṭaḥān, Musțafā Muḥammad. Al-Tarbiyah wa Dawruhā fì Tashkīl al-Sulūk. Mansūrah: Dār al-Wafā' lī al-Ṭibā'ah wa al-Nashr wa al-Tawzī', 2006.

Al-Zuhaylī, Wahbah. Al-Tafsìr al-Munīr fì al-'Aqīdah wa al-Sharī'ah wa al-Manhaj. Damsyiq: Dār al-Fikr, 1991. Azlina Abu Bakar. "Pembinaan Model Kesejahteraan Diri Remaja di Terengganu". Tesis Ph.D., Fakulti Pendidikan, Universiti Malaya, 2011.

Che Zarrina Sa'ari dan Sharifah Basirah Syed Muhsin. "Cadangan Model Psikoterapi Remaja Berasaskan Konsep Tazkiyah al-Nafs". Jurnal Usuluddin. Bil. 36, Julai-Disember 2016.

Che Zarrina Sa'ari et. al. "Terapi Spiritual Melalui Kaedah Tazkiyah al-Nafs oleh Syeikh Abdul Qadir al-Mandili Dalam Kitab Penawar Bagi hati”. Jurnal Akidah dan Pemikiran Islam (AFKAR). Bil 18, Special Issue 2016.

Ghazali bin Basri. "Peranan Pendidik Dalam Pembentukan Ummah" Jurnal Pendidikan Islam. Bill. 5, No. 6, Julai 1987.

Hayu A'la Aslami. "Konsep Tazkiyatun Nafs dalam Kitab 'Ihya 'Ulumuddin Karya Imam al-Ghazali'. Tesis MA, Fakultas Tarbiyah dan Ilmu Keguruan, Institut Agama Islam Negeri, 2016. 
Ishak bin Ismail. "Budaya Nilai-Nilai Keagamaan dan Disiplin Pelajar di Sekolah Menengah Agama Negeri Selangor Darul Ehsan". Tesis Ph.D., Fakulti Pendidikan, Universiti Kebangsaan Malaysia, 2012.

Kamarul Azmi b. Jasmi. "Guru Cemerlang Pendidikan Islam Sekolah Menengah Di Malaysia: Satu Kajian Kes". Tesis Ph.D., Fakulti Pendidikan, Universiti Kebangsaan Malaysia, 2010.

Kementerian Pelajaran Malaysia. Buku Panduan Pengurusan Asrama Sekolah. Bahagian Pengurusan Sekolah Harian, Kementerian Pelajaran Malaysia, t.t..

Kementerian Pelajaran Malaysia. Hal Ehwal Murid (19692003). Shah Alam: Giga Wise Network Sdn. Bhd., t.t..

Kementerian Pelajaran Malaysia. Modul Pembangunan Murid Asrama (MPMA). Putrajaya: Bahagian Sekolah, Kementerian Pelajaran Malaysia, 2007.

Khan, Mohammad Sharif. Education Religion and The Modern Age. New Delhi: Ashish Publishing House, 1990.

M. Akmansyah. "Eksistensi Guru (Mursyid) Dalam Pendidikan Spiritual Perspektif Abu Hamid al-Ghazali". al-Tadzkiyyah-Jurnal Pendidikan Islam. Bil. 6, No. 1, Julai 2015.

Maḥmūd, 'Ali 'Abd al-Halīm. Wasā'il al-Tarbiyah 'Inda al-Ikhwān al-Muslimīn. Qāhirah: Dār al-Tawzī' wa alNashr al-Islāmiyyah, 1994.

Mahsyuri. "Prinsip-Prinsip Tazkiyah al-Nafs Dalam Islam Dan Hubungan Dengan Kesihatan Mental". Jurnal Pemikiran Islam Bil. 37, No. 2, Januari 2012.

Mohd. Kamal b. Hassan et al. Pendidikan Koleksi Dakwah. Kuala Lumpur: Yayasan Dakwah Islamiah Malaysia, 1981.

Mohd. Majid Konting. Kaedah Penyelidikan Pendidikan. Kuala Lumpur: Dewan Bahasa dan Pustaka, 1990. 
Muhammad 'Uthman El-Muhammady. "Pendidikan Islam Menurut al-Nadwi: Satu Analisis". Jurnal Usuluddin. Bil. 11, Julai 2000.

Nik Safiah Nik Abdullah et.al. "Kepentingan Elemen Kerohanian Dalam Pelaksanaan Aktiviti MRSM Ulul Albab: Kajian Kes di MRSM Gemencheh, Negeri Sembilan". Journal of Global Business and Social Entrepreneurship. Bil. 2, No. 1, Jun 2015.

Norfadilah Abdul Rahman et.al.. "Pembangunan Kerohanian Berasaskan al-Muhasibi Dalam Menangani Gejala Sosial Masa Kini". e-Proceeding of The International Conference Of Intergration Knowledge. Bandung: http ://World Conference.net., 2014.

Norsidah Ahmad et.al. "Pelaksanaan Program Kecemerlangan Pembangunan Sahsiah Sekolah- Sekolah di Malaysia". International Journal of Religion Research In Education. Bil. 2, No. 1, Julai 2017.

Othman Lebar. Penyelidikan Kualitatif: Pengenalan kepada Teori dan Metod. Tanjong Malim: Universiti Pendidikan Sultan Idris, 2009.

Qal'ahj̄̄, Muḥammad Rawwās. Dirāsah Taḥlīliyyah li Shakhșiyyah al-Rasūl Muhammad S.A.W. Beirūt: Dār alNafā' is, 1996.

Quṭb, Muḥammad. Manhaj al-Tarbiyah al-Islāmiyyah. Qāhirah: Dār al- Shurūq, 1993.

Rohana Hamzah et.al. "Spiritual Education Development". International Journal of Islamic and Arabic Education. Bil. 2, No. 2, Januari 2010.

Rohana Hamzah et.al. "Pembangunan Jiwa Pendidik dalam Kalangan Bakal Pendidik”. Jurnal Teknologi (Social Sciences). Bil. 61, No. 1, Julai 2012.

Sābiq, al-Sayyid. Islāmunā. Qāhirah: Dār al-Fatḥ li I'lām al-'Arabī, 2001.

Sabitha Marican. Penyelidikan Sains Sosial, Pendekatan Pragmatik. Batu Caves: Edusystem Sdn. Bhd., 2009. 
Sa'id Hawwā. Al-Mustakhlaṣ fì Tazkiyah al-Nafs. Qāhirah: Dār al-Salām, 1995.

Sa'id Hawwā. Tarbiyatunā al-Rūhiyyah. Qāhirah: Dār alSalām, 1997.

Salasiah Hanin Hamjah. Pendekatan Kaunseling Spiritual Menurut al-Ghazali. Kuala Lumpur: Dewan Bahasa dan Pustaka, 2016.

Uma Sekaran. Research Methods for Business: A SkillBuilding. United States of American, John Wiley \& Son, Inc., 2009.

Zakaria Stapa. "Insan Kamil: Ciri dan Proses Pembentukan". Jurnal Akidah dan Pemikiran Islam (AFKAR), Bil. 2, No. 1, Jun 2001.

Zakaria Stapa. Akhlak dan Tasawwuf Islam. Kuala Lumpur: Berita Publishing Sdn. Bhd., 1995.

Zidni Nuran Noordin et.al. "Perbandingan Proses Tazkiyah al-Nafs Menurut Imam al-Ghazali dan Ibnu Qayyim". Jurnal al-Turath. Bil. 2, No. 1, Mac 2017. 